\title{
Radial incision and cutting for releasing severe stricture enables successful delivery of an over-the-scope clip
}

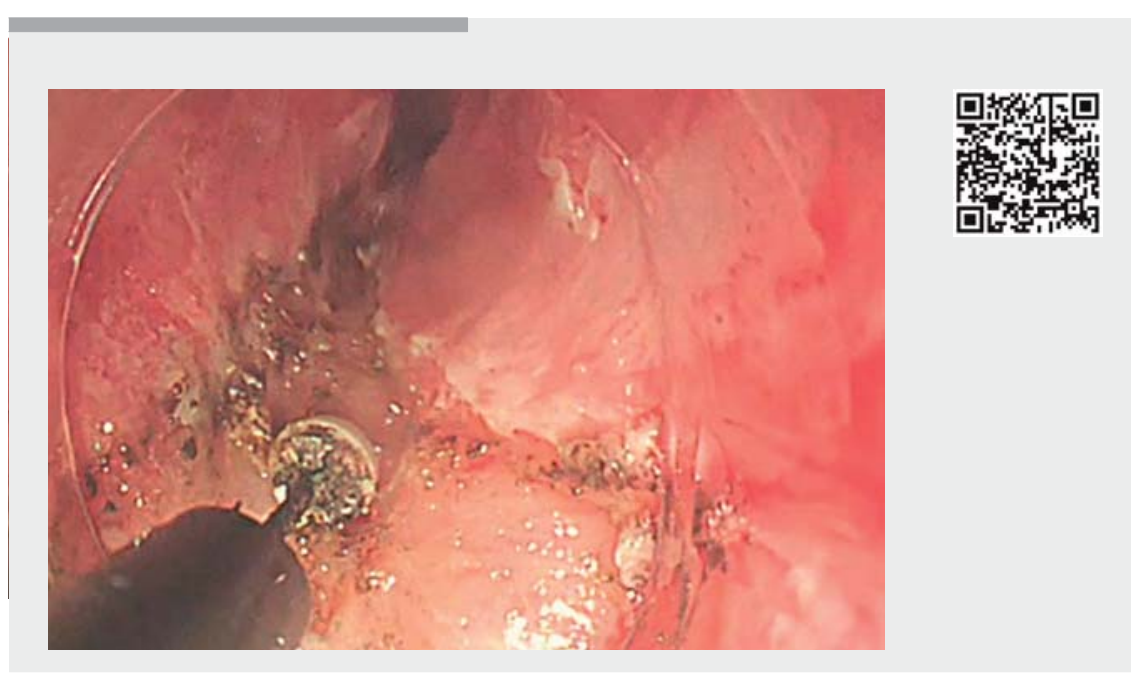

$\checkmark$ Video 1 Radial incision and cutting to release a benign, severe esophageal stricture enables successful passage of an over-the-scope clip (OTSC) beyond the stricture. The gastrocutaneous fistula was then completely closed with one OTSC deployment.

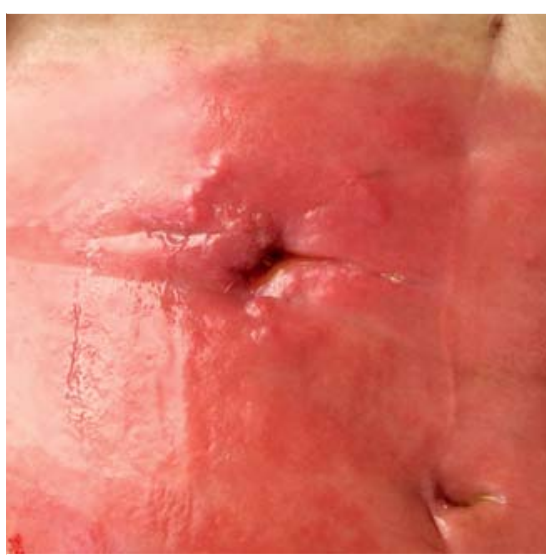

- Fig. 1 Gastrocutaneous fistula, cutaneous side, in an 81-year-old woman following percutaneous endoscopic gastrostomy. There is severe dermatitis due to leakage of gastric contents.

Nonhealing gastrocutaneous fistula (GCF), a rare refractory complication after percutaneous endoscopic gastrostomy, has traditionally required invasive surgery. Recently, the over-the-scope clip (OTSC) (Ovesco Endoscopy, Tübingen, Germany) has been reported to be a minimally invasive, effective device to

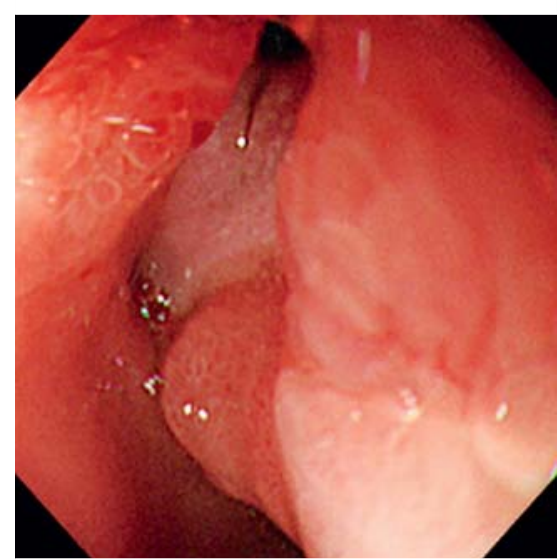

- Fig. 2 The gastrocutaneous fistula, located in the first portion of the duodenum.

achieve fistula closure [1]. However it is associated with one drawback: because the outer diameter of the OTSC application cap is large and the bear claws at the clip's tip are sharp, the presence of a severe gastrointestinal stricture makes delivery of an OTSC difficult. The standard treatment for refractory benign strictures, balloon dilation, is sometimes limited and an endoscopic radial incision and cutting technique has been developed as an alternative [2,3]. We describe the release, by means of radial incision and cutting, of a stenosis due to severe esophageal stricture; this allowed successful delivery of an OTSC and closure of the gastrointestinal fistula.

An 81-year-old woman presented with a 3-month history of non-healing GCF following percutaneous endoscopic gastrostomy. It had resulted in skin denudation caused by leakage of gastric contents ( $\mathbf{F i g} \mathbf{1}$ ). She underwent esophagogastroduodenoscopy, which showed the fistula in the inferior duodenal wall ( $\triangleright$ Fig.2). There was also a benign, severe esophageal stricture due to severe gastroesophageal reflux disease. After giving written informed consent, the patient underwent several sessions of endoscopic balloon dilation, which were unsuccessful in permitting passage beyond the stricture of the endoscope with the OTSC system ( $\mathbf{F i g . 3}$ ). The endoscopic radial incision and cutting method was then carried out and successfully released the esophageal stricture, thereby allowing OTSC delivery ( $\triangleright$ Fig.4). Finally, the fistula was completely closed by means of one OTSC deployment ( $>$ Fig.5). No procedure-related complications occurred.

This case shows that the radial incision and cutting technique is an effective option for OTSC delivery and deployment in patients with a benign, severe esophageal stricture.

Endoscopy_UCTN_Code_TTT_1AO_2AI 


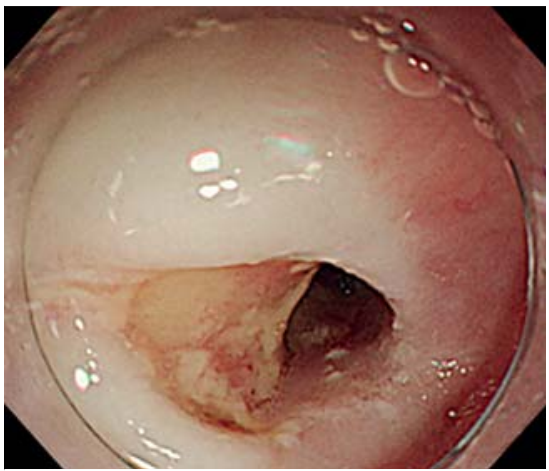

> Fig. 3 The severe esophageal stricture.

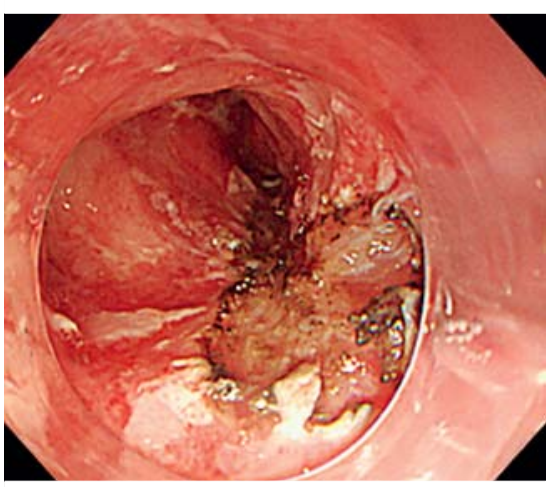

- Fig. 4 Release of the esophageal stenosis using the endoscopic radial incision and cutting technique, thereby allowing passage of the over-the-scope clip (OTSC) system.

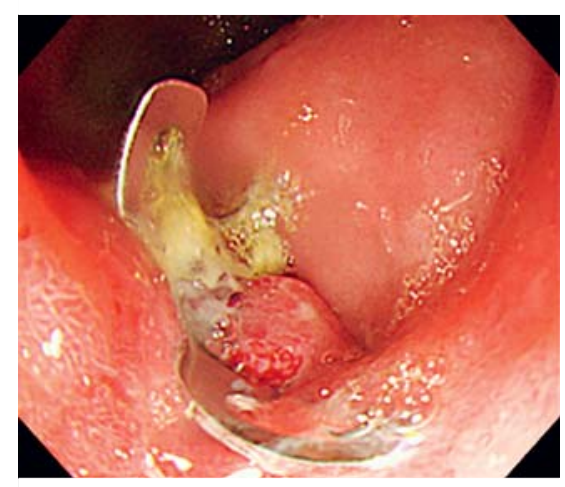

- Fig. 5 Endoscopic view shows successful over-the-scope clip (OTSC) deployment, with closure of the fistula.

\section{Competing interests}

The authors declare no conflicts of interest and have no financial arrangements with any company.

The authors

Shintaro Fujihara', Hideki Kobara', Noriko Nishiyama', Masahiko Kobayashi², Yasutaka Kokudo $^{2}$, Hirohito Mori ${ }^{1}$, Tsutomu Masaki ${ }^{1}$

1 Department of Gastroenterology and Neurology, Faculty of Medicine, Kagawa University, Kagawa, Japan

2 Department of Surgery, Kagawa Rosai Hospital, Marugame, Kagawa, Japan

\section{Corresponding author}

\section{Shintaro Fujihara, MD, PhD}

Department of Gastroenterology and Neurology, Faculty of Medicine, Kagawa University, 1750-1 Ikenobe, Miki-cho Kagawa 761-0793, Japan

Fax: +81-87-8912158

joshin@med.kagawa-u.ac.jp

\section{References}

[1] Schurr MO, Arezzo A, Ho CN et al. The OTSC clip for endoscopic organ closure in NOTES: device and technique. Minim Invasive Ther Allied Technol 2008; 17: 262-266

[2] Muto M, Ezoe Y, Yano T et al. Usefulness of endoscopic radial incision and cutting method for refractory esophagogastric anastomotic stricture (with video). Gastrointest Endosc 2012; 75: 965 - 972

[3] Yano T, Yoda Y, Satake H et al. Radial incision and cutting method for refractory stricture after nonsurgical treatment of esophageal cancer. Endoscopy 2013; 45: 316-319

\section{Bibliography}

DOI https://doi.org/10.1055/a-0871-1749

Published online: 12.4.2019

Endoscopy 2019; 51: E179-E180

(c) Georg Thieme Verlag KG

Stuttgart · New York

ISSN 0013-726X

\section{ENDOSCOPY E-VIDEOS \\ https://eref.thieme.de/e-videos}

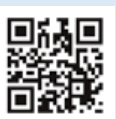

Endoscopy E-Videos is a free access online section, reporting on interesting cases and new

techniques in gastroenterological endoscopy. All papers include a high quality video and all contributions are freely accessible online.

This section has its own submission website at https://mc.manuscriptcentral.com/e-videos 